\section{Contribution of vegetables and cured meat to dietary nitrate and nitrite intake in Italian population: Safe level for cured meat and controversial role of vegetables}

Rossana Roila, ${ }^{1}$ Raffaella Branciari, ${ }^{1}$ Benedetta Staccini, ${ }^{2}$ David Ranucci, ${ }^{1}$ Dino Miraglia, ${ }^{1}$ Maria Serena Altissimi, ${ }^{2}$ Maria Lucia Mercuri, ${ }^{2}$

Naceur M. Haouet ${ }^{2}$

${ }^{1}$ Dipartimento di Medicina Veterinaria, Università degli Studi di Perugia; ${ }^{2}$ Istituto Zooprofilattico Sperimentale dell'Umbria e delle Marche "Togo Rosati”, Perugia (PG), Italy

\begin{abstract}
Nitrate and nitrite content was determined on a total of 900 samples of vegetables and cured meat and the nitrite and nitrate exposure assessment was evaluated for central Italy population based on the food consumption data reported by the national dietary surveys. The highest average content of nitrate was detected in rocket salad (4415 $\mathrm{mg} / \mathrm{kg})$ and radish $(3817 \mathrm{mg} / \mathrm{kg})$ and for cured meat in "Bresaola" (188 mg/kg) and in Bacon $(178 \mathrm{mg} / \mathrm{kg})$. The nitrite content was negligible both in vegetables than in cured meat. The average consumption among population resulted $3.45 \mathrm{~g} / \mathrm{kg}$ bw/die and $0.62 \mathrm{~g} / \mathrm{kg} \mathrm{bw} / \mathrm{die}$ for vegetables and cured meat respectively. The obtained data confirm that nitrate ADI was higher than the limits of $3.7 \mathrm{mg} / \mathrm{kg}$ bw/die for infants and was the highest exposure level for people of all ages. Cured meat consumption did not contribute to nitrate ADI exceedance neither as a mean nor as $99^{\text {th }}$ percentile of exposure.
\end{abstract}

\section{Introduction}

Nitrite and indirectly nitrate can represent, when taken in excessive amount with food consumption, a threat to human health. Although they are naturally present in a wide variety of foods, the concern is mostly addressed to nitrate and nitrite levels in cured meat because of the allowed use as additive ingredients (Sindelar et al., 2012; Efsa 2017). Nitrate is added as a precursor to nitrite that affects positively the appearance, flavor, safety, and quality of cured meats (Bedale et al., 2016). On the other hands, vegetables and drinking water contribute in large amount to nitrate (and nitrite) level in the diet, far more than cured meat (Bedale et al., 2016). Nitrate indeed is naturally present in all plant materials, especially vegetables and forage crops, and accumulate when the plant grows in a nitrate rich environment (Griesenbeck et al., 2009). Nitrate per se is relatively non-toxic but approximately $9 \%$ of all ingested nitrate is converted in saliva and in the gastrointestinal tract to the more toxic nitrite (Efsa, 2017a,b; Sindelar et al., 2012). In the stomach, nitrite reacts with amines and amides, to form a group of molecules known as $\mathrm{N}$-nitroso compounds (Sindelar et al., 2012) that have been classified by International Agency for Research on Cancer as probable carcinogens belonging to Group 2A (IARC, 2010). The exposure to endogenously formed $\mathrm{N}$-nitroso compounds had been associated with increased risks of cancer of the stomach, oesophagus and bladder (Loh et al., 2011). Furthermore, the nitrite is able to react with haemoglobin to form methaemoglobin and nitrate. Methaemoglobinemia represents a hazard for human health, especially for infants, due to the reduction of the oxygencarrying capacity of blood. In this context, the use of sodium and potassium nitrates $(\mathrm{E}$ 251, E 252) and nitrites (E 249, E 250) is regulated as food additives in the European Union (EU) according to the Regulation (EC) No 1333/2008 while the maximum allowed levels in vegetables are set only for nitrates in the Regulation (EC) No $1881 / 2006$. The nitrate and nitrite dietary exposure data available in literature are scarcely comparable as estimated only in general population and adults (Menard et al., 2008). Furthermore, several researches were focused on additive food-vectors only and some others solely on nitrate exposure via vegetable intake (Reinik et al., 2005; Tamme et al., 2006). The Acceptable Daily Intake (ADI) is established respectively by the European Commission's Scientific Committee on Food (SCF) and JECFA at 00.06 and $0-0.07 \mathrm{mg} / \mathrm{kg}$ body weight (bw) per day, for nitrite, and $3.7 \mathrm{mg} / \mathrm{kg}$ bw per day for nitrate (SCF, 1997; JECFA, 2002). Recently, the European Food Safety Authority has reevaluated the exposure to potassium and sodium nitrite (E 249, E 250) and to sodium and potassium nitrate (E 251, E 252) as food additives. The experts concluded that the exposure to these molecules resulting from their use as food additive does not lead to an exceedance of the ADI for the general population except for a slight exceedance in children. However, considering all sources of dietary nitrite and nitrate exposure together (food additives, natural presence and contamination), the ADI would be exceeded in infants, toddlers and children at
Correspondence: Raffaella Branciari, Dipartimento di Medicina Veterinaria, Università degli Studi di Perugia, Via San Costanzo 4, 06126 Perugia (PG), Italy. Tel.: +39.075.5857932 - Fax: +39.075.5857932. E-mail: raffaella.branciari@unipg.it

Key words: Food safety, Chemical hazards, Food additives, ADI.

Contributions: RR and RB contributed equally.

Conflict of interests: the authors declare no potential conflict of interests.

Funding: none.

Received for publication: 12 July 2018. Revision received: 21 September 2018 , Accepted for publication: 21 September 2018,

This work is licensed under a Creative Commons Attribution-NonCommercial 4.0 International License (CC BY-NC 4.0).

(C) Copyright R. Roila et al., 2018

Licensee PAGEPress, Italy

Italian Journal of Food Safety 2018; 7:7692

doi:10.4081/ijfs.2018.7692

the mean level and in people of all ages at the highest exposure (Efsa, 2017a and 2017b). Several authors have reported that the main source of nitrate in the diet is represented by vegetables (Santamaria, 2006; Sindelar et al., 2012; Menard et al., 2008). Nitrate-accumulating vegetables belong to the families of Brassicaceae (rocket, radish, mustard), Chenopodiaceae (beetroot, Swiss chard, spinach) and Amarantaceae; but also, Asteraceae (lettuce) and Apiaceae (celery, parsley) include species with high nitrate contents (Santamaria, 2006). Nitrate concentrations in vegetables depend on several factors such as: the biological properties of the plant culture, (day)light intensity, type of soil, temperature, humidity, frequency of plants in the field, plant maturity, vegetation period, harvesting time, size of the vegetable unit, storage time and source of nitrogen fertilization (Tamme et al., 2006). Despite the unquestioned beneficial effects of vegetables, representing a primary source of vitamins, minerals and antioxidant compounds, the amount of nitrate in vegetables is of great concern. The evaluation of the nitrate and nitrite levels in vegetables is therefore important in order to assess their safety for consumers. These products play a key role in the Italian population's diet, being consumed on a daily basis.

The aim of the present study was to 
estimate dietary exposure to nitrites and nitrates in five groups of population (infant/toddler, children, adolescent, adult and elderly people) quantifying these molecules content in vegetables and cured meat commonly consumed in central Italy.

\section{Materials and Methods}

\section{Nitrite and nitrate determination in food}

A total of 900 samples were analyzed for both the presence and the amount of nitrate and nitrite (Table 1). Samples were divided into 2 main groups, vegetables and cured meat, and were prepared according to the method previously reported by De Martin (2003) with some modifications. A finely ground sample $(5 \mathrm{~g})$ was placed into a 150 $\mathrm{mL}$ centrifuge tube to which $100 \mathrm{~mL}$ of high purity de-ionized water, obtained using a Milli-Q water purification system (Millipore, Bedford, MA, USA), and $50 \mu \mathrm{L}$ of sodium hydroxide $1 \mathrm{M}$ were added. The mixture was placed in water bath at $50^{\circ} \mathrm{C}$ for $30 \mathrm{~min}$ and subsequently vigorously shaken for $15 \mathrm{~min}$ using a vortex oscillator. An amount of $9 \mathrm{~mL}$ of extract was transferred into a $15 \mathrm{~mL}$ centrifuge tube with $1 \mathrm{~mL}$ of methanol and centrifuged at $4500 \mathrm{rpm}$ for $15 \mathrm{~min}$ at $4{ }^{\circ} \mathrm{C}$. A SPE column (C18/500 $\mathrm{mg}$ of $6 \mathrm{ml}$, ISOLUTER, International Sorbent Technology, Ystrad Mynach, UK) was activated with $2 \mathrm{~mL}$ methanol and $2 \mathrm{~mL}$ Milli-Q water. A total of $2 \mathrm{~mL}$ of the sample was loaded to saturation into the column and the eluate was discarded; another $2 \mathrm{~mL}$ of the sample were then passed through and collected in $15 \mathrm{~mL}$ test tubes. This sample was used for the determination of nitrites and nitrates by ion chromatography after filtration with $0.45 \mu \mathrm{m}$ nylon filter. A Dionex ICS 5000 ion chromatograph was employed with an automatic sampler, integrator, a 100 $\mu \mathrm{L}$ loop and a conductimetric detector (Dionex, Sunnyvale, CA, USA). An AG19 precolumn (Dionex) 4x50 mm was followed by an AS19 column 4x250 mm. The eluent was a mixture of water and $100 \mathrm{mM} \mathrm{NaOH}$ $(9: 1 \mathrm{v} / \mathrm{v})$; the chromatograph was run at room temperature with a flow rate of
$1 \mathrm{~mL} / \mathrm{min}$. Nitrite and nitrate standard solutions were used to construct a linear calibration curve in the range of $0.5 \mu \mathrm{g} / \mathrm{mL}$ to $20 \mu \mathrm{g} / \mathrm{mL}$ (average curve $\mathrm{Y}=0.0937 \mathrm{X}$ $0.0248 \mathrm{R}^{2}=0.9984$ for nitrate and $\mathrm{Y}=0.1371 \mathrm{x}-0.0117 \mathrm{R}^{2}=0.9987$ for nitrite). The method was in-house validated with a limit of detection of for nitrite and $20 \mathrm{mg} / \mathrm{kg}$ for nitrate, and limits of quantification of 30 $\mathrm{mg} / \mathrm{kg}$ and $40 \mathrm{mg} / \mathrm{kg}$ respectively. Intermediate precision (relative repeatability) is $5.9 \%$ of the content of both nitrite or nitrate in $\mathrm{mg} / \mathrm{kg}$ of analyzed sample), recovery was $97.81 \%$ and uncertainty $0.070 \mathrm{X}$. Results reproducibility was assessed by participations to proficiency tests (FAPAS, Food Analysis Performance Assessment Scheme, 2015) obtaining satisfactory $\mathrm{z}$-scores $(-2 ;+2)$.

\section{Estimated dietary exposure to nitrates and nitrites}

An assessment of the exposure of the central Italy population to nitrates and nitrites was carried out based on the food consumption data reported by the national

Table 1. Nitrate and nitrite mean content $(\mathrm{mg} / \mathrm{kg})$ for different vegetable and dry cured meat samples.

\begin{tabular}{|c|c|c|c|c|c|c|c|}
\hline & \multirow[t]{2}{*}{ N. } & \multicolumn{3}{|c|}{ Nitrate* (mg/kg) } & \multicolumn{3}{|c|}{ Nitrite* (mg/kg) } \\
\hline & & Range & Mean & $\pm \mathrm{SD}$ & Range & Mean & $\pm \mathrm{SD}$ \\
\hline \multicolumn{8}{|c|}{ Vegetables } \\
\hline Carrot (Daucus carota) & 8 & $<$ LOD -299 & 238 & 100 & $<\mathrm{LOD}$ & & \\
\hline Chard (Beta vulgaris var. cicla) & 2 & $1026-2430$ & 1728 & 993 & $<\mathrm{LOD}$ & & \\
\hline Eggplant (Solanum melongena) & 7 & $<\mathrm{LOD}-420$ & 399 & 151 & $<\mathrm{LOD}$ & & \\
\hline Garlic (Allium sativum) & 1 & & 111 & & $<\mathrm{LOD}$ & & \\
\hline Lettuce (Lactuca sativa L.) & 46 & $<\mathrm{LOD}-3660$ & 1079 & 974 & $<\mathrm{LOD}-23$ & 1.01 & 4.87 \\
\hline Onion (Allium сера) & 1 & & 69 & & $<\mathrm{LOD}$ & & \\
\hline Pepper (Capsicum annuum) & 2 & $<$ LOD -163 & 81 & 115 & $<\mathrm{LOD}$ & & \\
\hline Potato (Solanum tuberosum) & 7 & $73-223$ & 96 & 55 & $<\mathrm{LOD}$ & & \\
\hline Radish (Raphanus sativus) & 1 & $3650-3985$ & 3817 & 236 & $<\mathrm{LOD}$ & & \\
\hline $\begin{array}{l}\text { Red chicory "Radicchio" } \\
\text { (Cichorium intybus var.foliosum) }\end{array}$ & 2 & 281-711 & 496 & 304 & $<\mathrm{LOD}$ & & \\
\hline Rocket salad (Eruca vesicaria) & 12 & $1463-6724$ & 4415 & 1362 & $<\mathrm{LOD}-47$ & 16 & 21 \\
\hline Spices & 1 & & 90 & & $<\mathrm{LOD}$ & & \\
\hline Spinach (Spinacia oleracea) & 14 & $96-3559$ & 2036 & 1042 & $<$ LOD -32 & 8 & 16 \\
\hline Zucchini (Cucurbita pepo) & 9 & $15-973$ & 736 & 299 & $<\mathrm{LOD}$ & & \\
\hline \multicolumn{8}{|c|}{ Cured Meat } \\
\hline "Bresaola" & 6 & $<$ LOD -300 & 188 & 108 & $<$ LOD 126 & 25.67 & 49.67 \\
\hline "Capocollo" & 26 & $<$ LOD -304 & 69 & 77 & $<$ LOD -19 & 0.76 & 3.8 \\
\hline "Ciauscolo" salami & 66 & $<$ LOD -161 & 43 & 50 & & $<\mathrm{LOD}$ & \\
\hline Bacon & 11 & $<\mathrm{LOD}-497$ & 178 & 166 & $<\mathrm{LOD}-17$ & 7.7 & 8.15 \\
\hline Cured ham & 33 & $<$ LOD -169 & 21 & 44 & & $<\mathrm{LOD}$ & \\
\hline Dry fermented salami "Salame" & 568 & $<$ LOD -1046 & 69 & 97 & $<$ LOD -196 & 7.8 & 23.59 \\
\hline Dry fermented sausage "Salsiccia" & 72 & $<\mathrm{LOD}-493$ & 46 & 80 & $<\mathrm{LOD}-67$ & 5.03 & 14.65 \\
\hline "Guanciale" & 4 & $73-233$ & 142 & 78 & $<\mathrm{LOD}-32$ & 8 & 16 \\
\hline
\end{tabular}

*Expressed as $\mathrm{NaNO}_{2}$ and $\mathrm{NaNO}_{3}$ in cured meat and $\mathrm{NO}_{2}$ - and $\mathrm{NO}_{3}$ - in vegetables; data are expressed as lower bound. 
Italian dietary surveys (http://www.crea.gov.it/ consumi-alimentari, 2012) at a detailed level. Five age-based population groups were considered for the exposure assessment: infants/toddlers (0-2 years old), children (3-9 years old), adolescents (10-17 years old), adults (18-64 years old) and elderly (65-97 years old). The body weigh data for the considered groups, referred to the age classes sets in the national survey, were $11,26,53,70$ and $70 \mathrm{~kg}$ respectively. The mean and the $99^{\text {th }}$ percentiles of exposure were calculated per population group (Altissimi et al., 2017). Dietary nitrite and nitrate exposure were also reported as a percentage contribution to ADI (Efsa, 2017).

\section{Results and Discussion}

Results of nitrate and nitrite levels in vegetables and cured meats most commonly consumed by five central Italy population groups (infants/toddlers, children, adolescents, adults and elderly) are presented in Table 1. The high standard deviations indicate significant variations of the results obtained for individual product groups. Regarding the nitrate in vegetables, the results show a considerable variation of content within the same group. As described in literature, the nitrate content in vegetables depends on many factors, such as soil properties, fertilizer use, cultivation and weather conditions, which are unknown and whose effects are impossible to account for in this study; considering all these factors, wide ranges and large standard deviations may occur (Pennington, 1998). Another aspect to take in consideration is that nitrite and nitrate determination was performed on raw vegetables and some studies found that molecule's content could be reduced when the vegetables are washed or cooked (Leszczynska et al., 2009). The highest mean nitrate concentration was found in rocket salad (4415 mg/kg) followed by radish (3817 $\mathrm{mg} / \mathrm{kg})$, chard (1728 mg/kg), spinach (2036 $\mathrm{mg} / \mathrm{kg}$ ), lettuce (1079 mg/kg), zucchini (736 $\mathrm{mg} / \mathrm{kg}$ ) and red chicory "Radicchio" (496 $\mathrm{mg} / \mathrm{kg}$ ). In the other vegetable categories (carrot, eggplant, garlic, onion, pepper, potato and spices) the nitrate content was below $400 \mathrm{mg} / \mathrm{kg}$. The level of nitrate obtained in the present experiment was comparable to those found by other authors (Correia et al., 2010); moreover, our results are in accordance with Santamaria et al. (2006) who defined rocket salad as the highest nitrate-accumulating vegetable. Regarding nitrite in vegetable samples examined, the content was extremely low o below the limit of detection. Only five sample presented nitrite levels between 23 and $47 \mathrm{mg} / \mathrm{kg}$. These values are similar than those reported in literature for fresh vegetables samples (Correia et al., 2010). It is generally assumed that the nitrite levels in fresh leafy vegetables are usually less than 2 $\mathrm{mg} / \mathrm{kg}$ (Santamaria et al., 2006). EC Regulation No 1881/2006 set the maximum allowed levels of nitrate in some vegetables such as lettuce, spinach, rocket salad, iceberg type lettuce. The limits vary according to season with higher nitrate level permitted in winter compared with those grown in the summer. Lower limits are fixed for open-air grown lettuce than for lettuce grown under cover. Only one sample of spinach was above the limits set by the regulation. Concerning the nitrite and nitrate content in cured meat, the results are reported in Table 1. Nitrate and nitrite contents in different cured meat products analyzed were below the maximum allowed limit set by EC Regulation No 1333/2008 including subsequent amendments and additions. These products, on the basis of the production process, were considered in the specific category of dry cured ham and similar products (cured ham, "Bresaola", "Capocollo"), dry cured bacon and similar products (bacon and "Guanciale") with defined limits of $250 \mathrm{mg} / \mathrm{kg}$ nitrate and 150 $\mathrm{mg} / \mathrm{kg}$ nitrite expressed as $\mathrm{NaNO}_{2}$ and $\mathrm{NaNO}_{3}$ respectively. A maximum limit of $150 \mathrm{mg} / \mathrm{kg}$ of nitrate or nitrite can be added in the manufacture of dry fermented sausage ("Salame", dry fermented sausage "Salsiccia" and "Ciauscolo"). The average nitrate salts values in dry cured ham, dry cured bacon and dry fermented sausage were $55.6 \mathrm{mg} / \mathrm{kg}, 168 \mathrm{mg} / \mathrm{kg}$ and $35.4 \mathrm{mg} / \mathrm{kg}$, respectively, whereas the mean nitrite contents in dry cured ham, dry cured bacon and dry fermented sausage were $2.6 \mathrm{mg} / \mathrm{kg}$, $7.8 \mathrm{mg} / \mathrm{kg}$ and $7.4 \mathrm{mg} / \mathrm{kg}$, respectively. The amount of nitrate was higher than nitrite and this finding agrees with data reported in literature (Hsu et al., 2009). The explanation to such result is that some manufacturers prefer to add less nitrite than nitrate as stated by Oztekin et al. (2002). Furthermore, Hospital et al. (2015) and Honikel et al. (2008), demonstrate that nitrate levels can increase during fermentation in salami-type products because the nitrite added are oxidized into nitrate.

To estimate the average human potential exposure to nitrate and nitrite via vegetable and cured meat intake, the mean nitrate and nitrite concentrations in these two food categories were used in combination with the average daily consumption for population in central Italy. Potential human exposure to nitrates through vegetables was estimated on mean and $99^{\text {th }}$ percentile consumption values of five individual age groups (infants/toddlers aged 0-2 years and weighing $11 \mathrm{~kg}$, children aged 3-9 years and weighing $26 \mathrm{~kg}$, adolescents aged 10-17 years and weighing $53 \mathrm{~kg}$, adults aged 18-64 years and weighing $70 \mathrm{~kg}$, elderly adults aged 65-97 years and weighing $70 \mathrm{~kg}$ ) and the results are shown in Tables 2-6. The daily consumption of 5 categories of vegetables, root and bulb vegetables (carrot, garlic, onion, and radish), leafy vegetables (chard, lettuce, red chicory "Radicchio", rocket salad, spinach), fruit vegetables (eggplant, pepper, zucchini), potatoes and spices, ranged from a mean value of 2.39 for adults to $5.55 \mathrm{~g} / \mathrm{kg}$ bw/die for infant/toddlers and at the $99^{\text {th }}$ percentile ranged from 10.91 of elderly to $21.63 \mathrm{~g} / \mathrm{kg} \mathrm{bw} / \mathrm{die}$ for infant/toddlers. Among vegetables, potato

Table 2. Estimated nitrate intake from vegetables in infant/toddler aged 0-2 years and weighing $11 \mathrm{~kg}$.

\begin{tabular}{|c|c|c|c|c|c|c|}
\hline & \multicolumn{2}{|c|}{$\begin{array}{l}\text { Daily consumption } \\
\text { (g/kg bw/die) }\end{array}$} & \multicolumn{2}{|c|}{$\begin{array}{l}\text { Estimated daily intake } \\
\text { (mg/kg bw/die) }\end{array}$} & \multicolumn{2}{|c|}{ Contribution to ADI (\%) } \\
\hline & average & 99 $9^{\text {th }}$ percentile & average & $99^{\text {th }}$ percentile & average & 99 $9^{\text {th }}$ percentile \\
\hline Root and bulb vegetables & 0.73 & 1.81 & 0.591 & 1.466 & 15.98 & 39.63 \\
\hline Leaf vegetables & 1.27 & 7.82 & 2.266 & 13.954 & 61.25 & 377.14 \\
\hline Fruit vegetables & 1.55 & 6.18 & 0.791 & 3.153 & 21.37 & 85.21 \\
\hline Potatoes & 1.91 & 5.55 & 0.184 & 0.534 & 4.97 & 14.44 \\
\hline Spices & 0.09 & 0.27 & 0.008 & 0.024 & 0.22 & 0.66 \\
\hline Total & 5.55 & 21.63 & 3.840 & 19.131 & 103.79 & 517.08 \\
\hline
\end{tabular}


represents the most consumed class by all groups on average, especially for children, followed by fruit vegetable for infants/toddlers, root and bulb vegetables for children and leaf vegetables for adolescents and adults. An exception is represented by elderly people who consumes more leafy vegetables than potatoes. The average consumption of vegetables in Italian population is lower than in China while it is higher than that of north Europe (Correia et al., 2010; Zhong et al., 2002). Data of nitrate dietary exposure as well as the contribution to ADI for five individual age groups in central Italy were reported in Tables 2-6. The total nitrate intake calculated from 5 categories of vegetables ranged from a mean value of $1.22 \mathrm{mg} / \mathrm{kg}$ bw/die to $3.84 \mathrm{mg} / \mathrm{kg}$ bw/die for adolescent and infant/toddlers and from 12.83 to 19.12 for $99^{\text {th }}$ percentile for children and infant/toddlers, respectively.

Table 3. Estimated nitrate intake from vegetables in children aged 3-9 years and weighing $26 \mathbf{~ k g}$.

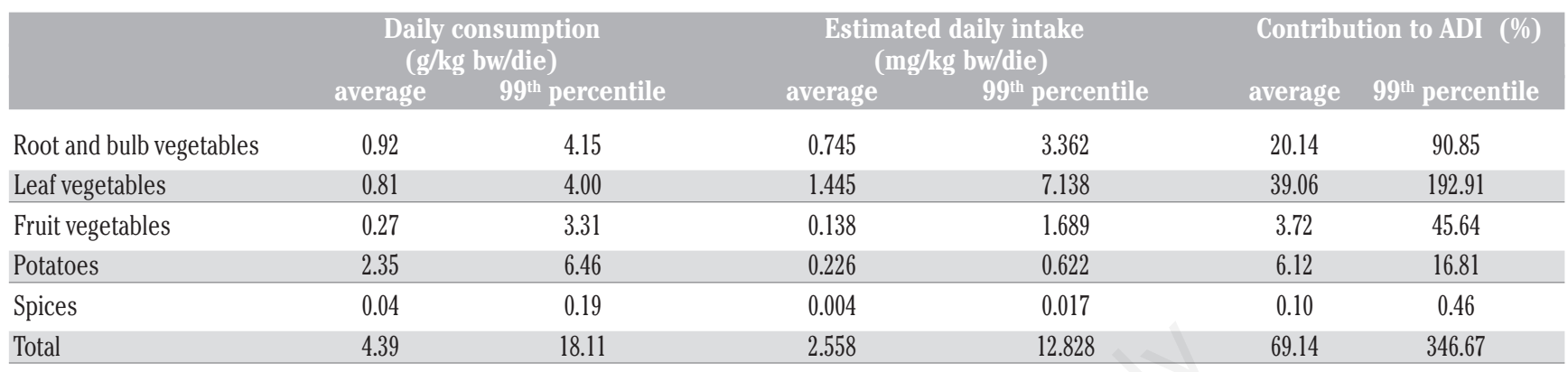

Table 4. Estimated nitrate intake from vegetables in adolescents aged 10-17 years and weighing $53 \mathrm{~kg}$.

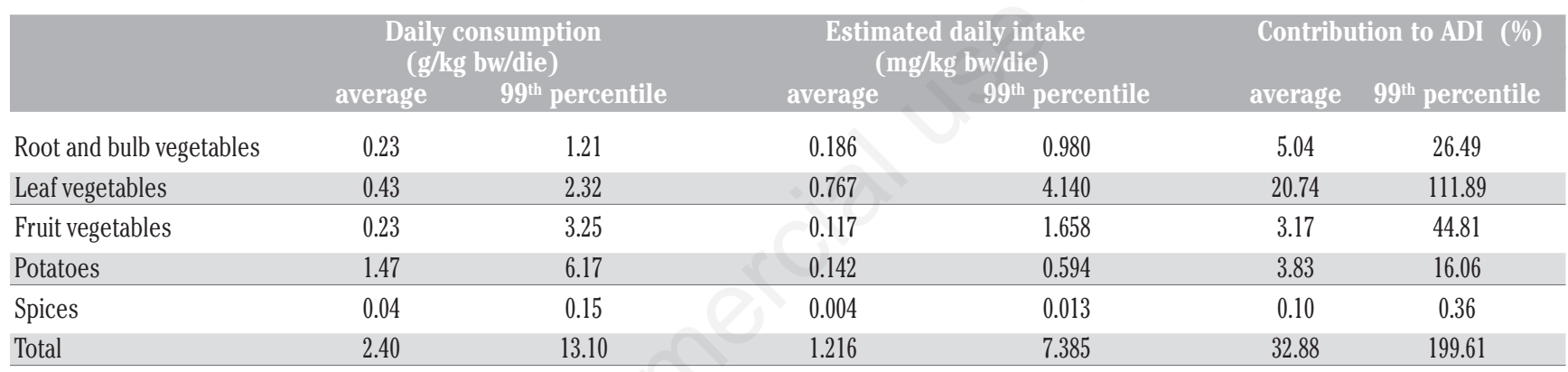

Table 5. Estimated nitrate intake from vegetables in adults aged 18-64 years and weighing $70 \mathrm{~kg}$.

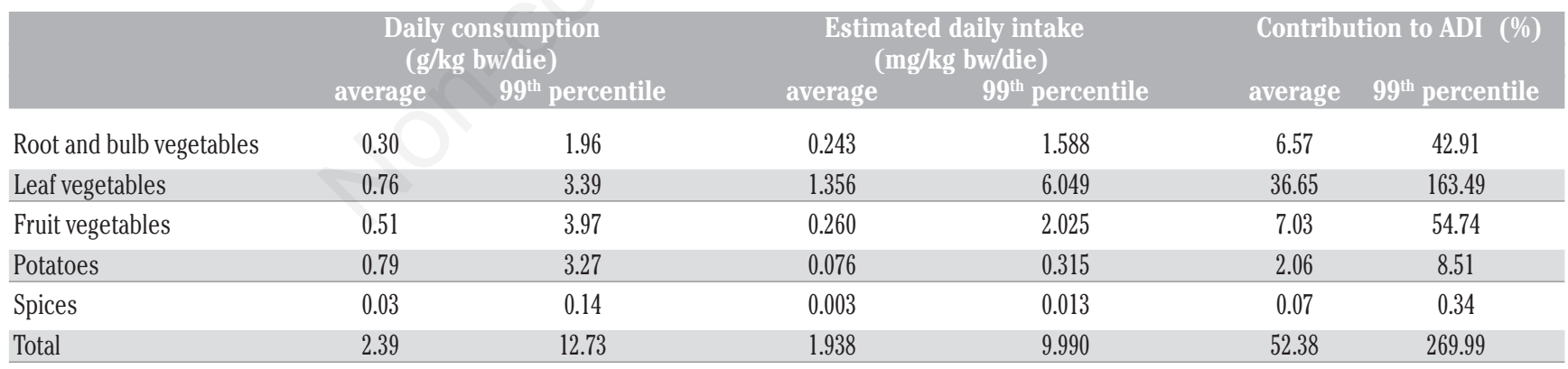

Table 6. Estimated nitrate intake from vegetables in elderly aged 65-97 years and weighing $70 \mathrm{~kg}$.

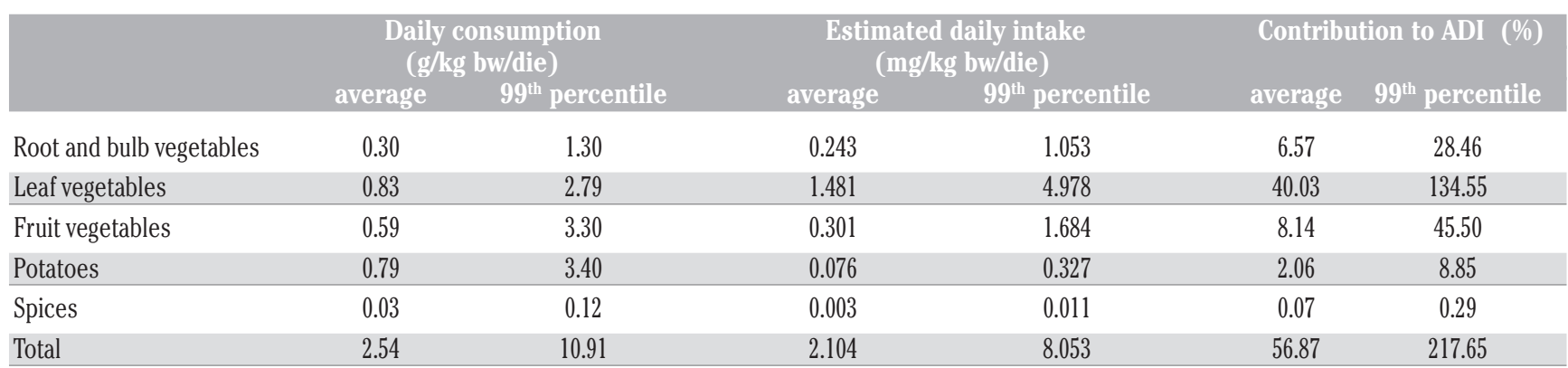


Table 7. Estimated nitrates and nitrite intake from meat products in central Italy population.

\begin{tabular}{|c|c|c|c|c|c|c|c|c|c|c|}
\hline & \multirow{2}{*}{\multicolumn{2}{|c|}{$\begin{array}{l}\text { Daily consumption } \\
\text { (g/kg bw/die) }\end{array}$}} & \multicolumn{4}{|c|}{ Nitrate } & \multicolumn{4}{|c|}{ Nitrite } \\
\hline & & & \multicolumn{2}{|c|}{$\begin{array}{c}\text { Estimated daily intake } \\
\text { (mg/kg bw/die) }\end{array}$} & \multicolumn{2}{|c|}{$\begin{array}{r}\text { Contribution to ADI (\%) } \\
\text { (mg/kg bw/die) }\end{array}$} & \multicolumn{2}{|c|}{$\begin{array}{l}\text { Estimated } \\
\text { daily intake }\end{array}$} & \multicolumn{2}{|c|}{$\begin{array}{c}\text { Contribution to ADI } \\
(\%)\end{array}$} \\
\hline & average & $\begin{array}{c}99^{\text {th }} \\
\text { percentile }\end{array}$ & average & $\begin{array}{l}99^{\text {th }} \\
\text { percentile }\end{array}$ & average & $\begin{array}{c}99^{\text {th }} \\
\text { percentile }\end{array}$ & average & $\begin{array}{c}99^{\text {th }} \\
\text { percentile }\end{array}$ & average & $\begin{array}{c}99^{\text {th }} \\
\text { percentile }\end{array}$ \\
\hline Infants/toddlers & 1.00 & 3.64 & 0.048 & 0.175 & 1.30 & 4.73 & 0.004 & 0.016 & 6.15 & 22.37 \\
\hline Children & 0.92 & 2.77 & 0.044 & 0.133 & 1.20 & 3.60 & 0.004 & 0.012 & 5.65 & 17.02 \\
\hline Adolescents & 0.51 & 1.38 & 0.025 & 0.066 & 0.66 & 1.79 & 0.002 & 0.006 & 3.13 & 8.48 \\
\hline Adults & 0.40 & 1.74 & 0.019 & 0.084 & 0.52 & 2.26 & 0.002 & 0.007 & 2.46 & 10.69 \\
\hline Elderly adults & 0.29 & 1.14 & 0.014 & 0.055 & 0.38 & 1.48 & 0.001 & 0.005 & 1.78 & 7.01 \\
\hline
\end{tabular}

The average nitrate intake of infant/toddler exceeds safe levels set by JECFA (2002) (3.7 $\mathrm{mg} / \mathrm{kg}$ bw per day); for the other groups, the level was below the limit. Considering the $99^{\text {th }}$ percentile values calculated in the present study, the nitrate intake is higher than the limit in all population groups investigated; this is primarily due to the remarkable contribution of leafy vegetables. The nitrate intake estimated in this study is higher than the intake estimated for UK and Denmark populations and lower than that of China (Zhong et al., 2002). These results are probably due to the heavy consumption of vegetables in China and the relatively scarce one in North Europe countries, in comparison to Italian habits (Zhong et al., 2002). Vegetables as a whole have a great impact on nitrate daily dietary intake contributing, at the mean level, approximately $104 \%, 69 \%, 33 \%, 52 \%$, and $57 \%$ to total ADI for each of the age groups respectively (infants/toddlers, children, adolescents, adults and elderly). Is important to remark that for infants/toddlers the intake of nitrate through vegetables exceeds safe levels set by JECFA (1998). Mainly due to the high content of nitrates in leafy vegetables, this food category contributes to $\mathrm{ADI}$ at the highest level in all the considered population groups, ranging from $21 \%$ for adolescents to $61 \%$ for infants/toddlers. This result is in contrast to that reported by De Martin (2003) who stated that, for children, the intake is lower because they eat less salad vegetables. The second vegetable category that contributes most to ADI is represented by fruit vegetables for infants/toddles, adults and elderly and by root and bulb vegetables for children and adolescents. An exceeding nitrate ADI, primarily due to the contribution of vegetables, was already reported in literature mainly for the population with a high rate of vegetables consumption (Correia et al., 2010). Regarding nitrite, the content found in this study was on average extremely low or below the limit of detection and consequently the contribution to dietary intake and to ADI is irrelevant (data not shown). Efsa (2017a and 2017b) considered that using the nitrate-to-nitrite conversion factor of $9 \%$ a dose corresponding to the ADI of $3.7 \mathrm{mg} / \mathrm{kg}$ bw per day will be converted into $0.25 \mathrm{mg}$ nitrite ion $/ \mathrm{kg}$ bw per day, therefore for all categories considered nitrate contributes to nitrites ADI exceedance. Human exposure to nitrate and nitrite through cured meat intake was estimated on mean and $99^{\text {th }}$ percentile consumption values on the five age groups above mentioned, and the results are shown in Table 7. Values are presented for a unique food category that assembles all the cured meat in which nitrate and nitrite content was analytically determined. For all consumers categories considered, the cured meat consumption ranged from a mean value of $0.29 \mathrm{~g} / \mathrm{kg} \mathrm{bw} / \mathrm{die}$ to $1.00 \mathrm{~g} / \mathrm{kg}$ bw/die and from 1.14 to 3.64 for $99^{\text {th }}$ percentile, for elderly and infant/toddlers respectively. The nitrate intake of cured meat ranged from a mean value of $0.01 \mathrm{mg} / \mathrm{kg}$ bw/die to 0.05 $\mathrm{mg} / \mathrm{kg}$ bw/die and from 0.06 to 0.18 for $99^{\text {th }}$ percentile, for elderly and infant/toddlers respectively. The nitrite intake estimated in this study ranged from a mean value of 0.001 $\mathrm{mg} / \mathrm{kg}$ bw/die for elderly to $0.004 \mathrm{mg} / \mathrm{kg}$ bw/die for infant/toddlers and children and from 0.005 to 0.016 for $99^{\text {th }}$ percentile, for elderly and infant/toddlers respectively.

The cured meat contribution to ADIs is scarce, ranging, for a mean level of nitrate, from $0.38 \%$ for elderly and $1.30 \%$ for infant/toddler, and from $1.78 \%$ for elderly to $6.15 \%$ for infant/toddler, for nitrite. Even when the $99^{\text {th }}$ percentile of nitrate and nitrite intake is considered; the lowest values are attributed to elderly whereas the highest values are attributed to infant/toddler. Regarding nitrate and nitrite intake for cured meat for the studied population, the level is widely lower than the safely limits and are similar to that reported in literature (Hsu et al., 2009). Many authors highlight the role of vegetables as a primary source of dietary nitrate. Ysart et al. (1999) showed that vegetables contributed approximately $70 \%$ of the nitrate dietary exposure of consumers in the UK. In a study in Poland, vegetables and their derivatives supplied 94-98\% of nitrate (Wawrzyniak et al., 1999). Similarly, Petersen (1999) identified vegetables as the most important contributors of nitrate. Although vegetable is one of the major sources of dietary exposure to nitrate, studies have reported that the consumption of vegetables could decrease incidences of cancer. This is probably due to antioxidant compounds (ascorbate, tocopherol, bcarotene, phenol compounds, indol) present in vegetables that could contribute to suppress the formation of carcinogenic agents, such as nitrosamines (Chung et al., 2003). Therefore, in order to profit as much as possible, the undoubted benefits of vegetables, it is advisable to pursue more responsible agricultural practices able to provide consumers with safer vegetables products, thus avoiding a prolonged and excessive consumption of vegetables with such a high nitrate content exceeding the ADI.

\section{Conclusions}

The results reported in this study concerning nitrate and nitrite exposure assessment for population of central Italy are in accordance to what recently reported by EFSA who stated that consumers exposure to nitrite and nitrate as food additives is within safe levels for all population groups. Nevertheless, a particular attention should be paid to the nitrate intake via vegetables especially in specific categories such as infants and vegetarians.

\section{References}

Altissimi MS, Roila R, Branciari R, Miraglia D, Ranucci D, Framboas M, Haouet N, 2017. Contribution of street food on dietary acrylamide exposure by youth 
aged nineteen to thirty in Perugia, Italy. Ital J Food Safety 6.

Bedale W, Sindelar JJ, Milkowski AL, 2016. Dietary nitrate and nitrite: Benefits, risks, and evolving perceptions. Meat Sci 120: 85-92.

Chung SY, Kim JS, Kim M, Hong MK, Lee JO, Kim CM, Song IS, 2003. Survey of nitrate and nitrite contents of vegetables grown in Korea. Food Addit Contam 20: 621-28.

Correia M, Barroso Â, Barroso MF, Soares D, Oliveira MBPP., Delerue-Matos C, 2010. Contribution of different vegetable types to exogenous nitrate and nitrite exposure. Food Chem 120: 960-66.

De Martin S, Restani P, 2003. Determination of nitrates by a novel ion chromatographic method: occurrence in leafy vegetables (organic and conventional) and exposure assessment for Italian consumers. Food Addit Contam 20: 787-92.

EFSA Panel on Food Additives and Nutrient Sources added to Food (ANS), Mortensen A, Aguilar F, Crebelli R, Di Domenico A, Dusemund B, Frutos MJ, Galtier P, Gott D, Gundert-Remy U, Lambrè $\mathrm{C}$, Leblanc JC, Lindtner $\mathrm{O}$, Moldeus P, Mosesso P, Oskarsson A, Parent-Massin D, Stankovic I, Waalkens-Berendsen I, Antonius Woutersen R, Wright M, Van den Brandt $\mathrm{P}$, Fortes $\mathrm{C}$, Merino L, Toldrà F, Arcella D, Christodoulidou A, Abrahantes JC, Barrucci F, Garcia A, Pizzo F, Battacchi D, Younes M, 2017a. Re-evaluation of potassium nitrite (E 249) and sodium nitrite (E 250) as food additives. Efsa J 15: e 04786.

EFSA Panel on Food Additives and Nutrient Sources added to Food (ANS), Mortensen A, Aguilar F, Crebelli R, Di Domenico A, Dusemund B, Frutos MJ, Galtier P, Gott D, Gundert-Remy U, Lambrè $\mathrm{C}$, Leblanc JC, Lindtner $\mathrm{O}$, Moldeus P, Mosesso P, Oskarsson A, Parent-Massin D, Stankovic I, Waalkens-Berendsen I, Antonius Woutersen R, Wright M, Van den Brandt $\mathrm{P}$, Fortes C, Merino L, Toldrà F, Arcella D, Christodoulidou A, Barrucci F, Garcia A, Pizzo F, Battacchi D, Younes M, 2017b. Re-evaluation of sodium nitrate (E 251) and potassium nitrate (E 252) as food additives. Efsa J 15: e04787.

European Regulation, 2006. Regulation of the European Communities of 19
December 2006 setting maximum levels for certain contaminants in foodstuffs, 1881/2006/CE. In: Official Journal, L 364/5, 20/12/2006.

European Regulation, 2008. Regulation of the European Parliament and of the Council of 16 December 2008 on food additives, 1333/2008/CE. In: Official Journal, L 354/16, 31/12/2008.

Honikel KO, 2008. The use and control of nitrate and nitrite for the processing of meat products. Meat Sci 78: 68-76.

Griesenbeck, J. S., Steck, M. D., Huber, J. C., Sharkey, J. R., Rene, A. A., \& Brender, J. D. (2009). Development of estimates of dietary nitrates, nitrites, and nitrosamines for use with the Short Willet Food Frequency Questionnaire. Nutrition journal, 8(1), 16.

Hospital XF, Carballo J, Fernández M, Arnau J, Gratacós M, Hierro E, 2015. Technological implications of reducing nitrate and nitrite levels in dry-fermented sausages: Typical microbiota, residual nitrate and nitrite and volatile profile. Food Control 57: 275-81.

Hsu J, Arcot J, Lee NA, 2009. Nitrate and nitrite quantification from cured meat and vegetables and their estimated dietary intake in Australians. Food Chem 115: 334-39.

International Agency For Research On Cancer, World Health Organization, 2010. Ingested Nitrate and Nitrite, and Cyanobacterial Peptide Toxins. IARC Monographs on the Evaluation of Carcinogenic Risks to Humans, Volume 94. Lyon (France).

Joint F. A. O., WHO Expert Committee on Food Additives, 2002. Evaluation of certain food additives and contaminants. Fifty-ninth report of JECFA. Joint FAO/WHO Expert Committee on Food Additives, WHO Tech Reports Series 913: 20-32.

Leszczyńska T, Filipiak-Florkiewicz A, Cieślik E, Sikora E, Pisulewski PM, 2009. Effects of some processing methods on nitrate and nitrite changes in cruciferous vegetables. J Food Compos Anal 22: 315-21.

Loh YH, Jakszyn P, Luben RN, Mulligan AA, Mitrou PN, Khaw KT, 2011. Nnitroso compounds and cancer incidence: the European Prospective Investigation into Cancer and Nutrition (EPIC)-Norfolk Study-. Am J Clinl Nut 93: 1053-61.
Menard C, Heraud F, Volatier JL, Leblanc JC, 2008. Assessment of dietary exposure of nitrate and nitrite in France. Food Addit Contam 25: 971-88.

Öztekin N, Nutku MS, Erim FB, 2002. Simultaneous determination of nitrite and nitrate in meat products and vegetables by capillary electrophoresis. Food Chem 76: 103-6.

Pennington JA, 1998. Dietary exposure models for nitrates and nitrites. Food Control 9: 385-95.

Petersen A, Stolze S, 1999. Nitrate and nitrite in vegetables on the Danish market: content and intake. Food Addit Contam 19: 524-32.

Reinik M, Tamme T, Roasto M, Juhkam K, Jurtšenko S, Tenńo T, Kiis A, 2005. Nitrites, nitrates and $\mathrm{N}$-nitrosoamines in Estonian cured meat products: Intake by Estonian children and adolescents. Food Addit Contam 22: 1098-1105.

Santamaria P, 2006. Nitrate in vegetables: toxicity, content, intake and $\mathrm{EC}$ regulation. J Sci Food Agr 86: 10-17.

Scientific Committee on Food SCF, 1997. Assessment of dietary intake of nitrates by the population in the European Union, as a consequence of the consumption of vegetables, in Reports on tasks for scientific cooperation: report of experts participating in Task 3.2.3, ed by European Commission, Brussels $p$ 34.

Sindelar JJ, Milkowski AL, 2012. Human safety controversies surrounding nitrate and nitrite in the diet. Nato Sci S A Lif Sci 26: 259-66.

Tamme T, Reinik M, Roasto M, Juhkam K, Tenno T, Kiis A, 2006. Nitrates and nitrites in vegetables and vegetablebased products and their intakes by the Estonian population. Food Addit Contam 23: 355-61.

Wawrzyniak A, Gronowska-Senger A, Gorecka K, 1999. The evaluation of nitrates and nitrites food intake among Polish households in 1991-1995. Roczniki Panstwowego Zakladu Higieny 50: 269-87.

Ysart G, Miller P, Barrett G, Farrington D, Lawrance P, Harrison N, 1999. Dietary exposures to nitrate in the UK. Food Addit Contam 16: 521-32.

Zhong W, Hu C, Wang M, 2002. Nitrate and nitrite in vegetables from north China: content and intake. Food Addit Contam 19: 1125-29. 